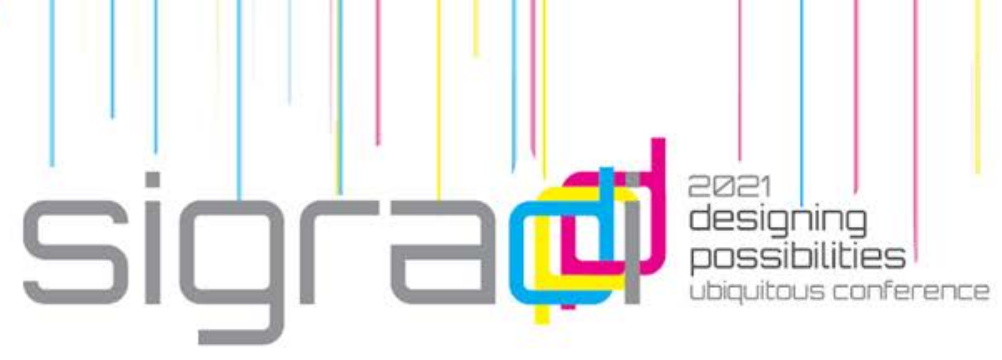

\title{
Designing Possible Futures: An Approach to Design Fiction in Architecture
}

\author{
Patrícia Turazzi Luciano ${ }^{1}$, Arthur Stofella ${ }^{1}$, Gladys Ilka Klein Taparello${ }^{1}$, Carlos \\ Eduardo Versola Vaz ${ }^{1}$ \\ ${ }^{1}$ Universidade Federal de Santa Catarina, Brasil \\ patriciaturazzi@gmail.com \\ a.stofella@hotmail.com \\ gladystaparello@gmail.com \\ cevv00@gmail.com
}

\begin{abstract}
Among several possible approaches for design process, Design Fiction stimulates the production of fictional universes in the search for innovation, exploration and creative provocation for the development of built environments. The aim of this article is to present results of the exploration of this approach in the context of architectural projects, based on the works of Markussen and Knutz (2013) and Plowright (2020). The work proposal for two workshops through webconference was based on fiction works pre-selected, from which students could choose at least one to use its narrative as a foundation to develop their own project. Thus, all three projects developed explore socio-technical, ecological and emotional characteristics of the inhabitants of created narratives, bringing them closer to an approach that has a greater focus on the relationship and interaction between user and built environment.
\end{abstract}

Keywords: Design fiction, Design process, User-environment interaction, Possible worlds theory.

\section{Introdução}

O Design Fiction é um campo emergente dentro das áreas da interação humano-computador e do design de interação (Markussen \& Knutz, 2013) e o design como um todo (Plowright, 2020), sendo pouco estudado nas escolas de arquitetura. A abordagem possui foco não somente na questão de problemasolução, mas em uma aproximação focada no relacionamento e na interatividade entre o usuário e o artefato projetado, que extrapola a realidade 
para propor alternativas futuras possíveis mas não necessariamente preditivas (Plowright, 2020). Essas alternativas possibilitam amplificar desenvolvimentos sociais e tecnológicos atuais de maneira a observar o futuro para refletir sobre o presente (Lupton, 2017).

A criação e o uso de protótipos condizentes com o contexto ficcional proposto (protótipos diegéticos) no processo de projeto auxiliam na descrença em relação à mudanças possíveis na realidade (Sterling, 2012), estimulando o questionamento sobre o projeto por meio da exploração, da inovação e da provocação criativa (Bleecker, 2009). Os protótipos diegéticos também podem servir como ferramenta de comunicação e visualização, além de uma fonte de inspiração e motivação para a elaboração de projetos conceituais (Tanenbaum, 2014).

Portanto, neste artigo optou-se por direcionar o processo de projeto por meio da abordagem da Design Fiction, partindo de referências de diferentes narrativas em diversas mídias, buscando compor uma perspectiva sóciotecnológica. O objetivo desta pesquisa é explorar as possibilidades de incorporação deste método no ensino de projeto arquitetônico, com base em workshops desenvolvidos com estudantes em 2021.

\subsection{Processo de Projeto}

O processo de projeto tradicional dos ateliês dos cursos de arquitetura tem por base a dupla problema-solução, podendo ser definido como, dentre os muitos estudos que abordam esse tópico, uma sucessão de etapas originadas a partir da definição de um problema (Broadbent \& Ward, 1969), um processo com abordagens iniciais relacionadas à problemática de projeto, ou uma base para alcançar uma solução a compreensão e resposta a um problema projetual (Lawson, 2011).

Esse foco na resposta a um problema foi apontado por Schon (1984) como limitador da compreensão da própria problemática, uma vez que é necessário realizar um recorte da situação para ser possível compreender e gerar uma solução. Esse recorte limita uma compreensão mais unificada da arquitetura em sua complexidade como espaço das dinâmicas humanas nas cidades.

\subsection{Fundamentos do Design Fiction}

Há um consenso geral entre os conceitos-chave que devem estar presentes na abordagem por meio do design fiction: (1) suspensão da descrença na previsão de um futuro próximo; (2) artefatos, ou protótipo diegéticos, presentes por meio de estruturas narrativas; (3) e a compreensão desses artefatos como representações sociotécnicas em vez de simples objetos técnicos (Plowright, 2020). 
O design fiction, ao utilizar narrativas de outras mídias, requer do praticante a suspensão da descrença, um ponto explicado pela teoria dos mundos possíveis de Ryan (2001). Essa teoria apresenta a realidade composta por muitas possibilidades de mundos, hierarquizados, com um deles ocupando o centro do universo - o "real" no momento, enquanto os demais são possibilidades, sendo necessário alguma ponte com o mundo real para ter a relação de acessibilidade (Ryan, 2001).

O critério de acessibilidade é o que distingue um mundo possível de um impossível dentro dessa teoria. Para recentralizar um mundo, ou seja, realocar o "real" no momento, o observador precisa realizar um esforço consciente de compreender o mundo que está sendo centralizado para explorar os desdobramentos possíveis - futuros possíveis, dentro das leis ontológicas da realidade em questão. A suspensão da descrença ocorre quando o leitor da mídia aceita, de forma voluntária, as premissas de uma narrativa como verdadeiras (Ryan, 2001).

No design fiction, a suspensão da descrença do leitor em relação a um futuro plausível é reforçada pelo protótipo diegético, que funciona como uma extensão da realidade. A ponte entre os mundos possíveis é o que orienta uma proposta não baseada apenas na fantasia, sendo para isso necessário do leitor uma auto-consistência, tanto no mundo real quanto no mundo criado da narrativa (Kirby, 2010; Plowright, 2020). Assim, o design fiction levanta questões de como os cenários hipotéticos poderiam estabelecer condições para a experimentação e desenvolvimento de projetos em futuros possíveis mas pouco preditivos (Knutz et al., 2014).

O conceito "diegese" está relacionado ao mundo ficcional criado, assim o protótipo diegético é considerado um objeto real que possui uma funcionalidade e é naturalmente utilizado pelos habitantes desse mundo (Kirby, 2010), possuindo um papel ativo dentro da narrativa e implicando uma diferença em relação a outros objetos que servem apenas como um tipo de decoração. Os protótipos instigam uma retórica visual e narrativa adicional especificamente contextualizada. Essa contextualização do artefato, que respeita as leis ontológicas dentro do mundo possível, é devidamente realizada por meio do desenvolvimento de uma micro-narrativa e um cenário com base referencial em uma narrativa de mídia pré-selecionada. De acordo com Kirby (2010), o protótipo diegético permite mapear as possibilidades sociais, políticas, econômicas e práticas de uma tecnologia antes mesmo de que seja considerada para ser desenvolvida.

Os elementos apresentados na narrativa também devem possuir uma certa lógica para que o efeito seja percebido (Plowright, 2020), de maneira que devem seguir um determinado conjunto de regras pré-estabelecidas, mesmo que sejam artefatos que não existam na realidade fora da narrativa (Tanenbaum, 2014). Plowright (2020) diz que, devido a essa necessidade de respeitar esse grupo de regras, o artefato diegético é co-criado em conjunto com o contexto sócio-cultural no qual existe. São artefatos como representação sociotécnica, co-dependentes dos valores sociais, políticos, 


\begin{tabular}{|c|c|c|}
\hline Etapa & Resultados da etapa de planejamento & Produto do planejamento \\
\hline $\begin{array}{l}\text { Referencial } \\
\text { teórico }\end{array}$ & $\begin{array}{l}\text { Pesquisa bibliográfica de artigos } \\
\text { científicos com a compreensão do processo } \\
\text { tradicional e como o design fiction já foi } \\
\text { utilizado, com quais objetivos e resultados } \\
\text { alcançados. }\end{array}$ & $\begin{array}{l}\text { Base para planejamento da } \\
\text { estrutura das oficinas quanto ao tempo } \\
\text { necessário, estrutura e formas de } \\
\text { avaliação. }\end{array}$ \\
\hline $\begin{array}{l}\text { Estrutura e } \\
\text { estratégia }\end{array}$ & $\begin{array}{l}4 \text { pontos principais: Disseminar o } \\
\text { método Design Fiction; Discutir o impactos } \\
\text { de novas tecnologias; Analisar exemplos } \\
\text { contextualizados; Desenvolver propostas de } \\
\text { projeto utilizando o método. }\end{array}$ & $\begin{array}{l}\text { Organização da estrutura da } \\
\text { oficina; Definição do tamanho das } \\
\text { equipes participantes; e Produção do } \\
\text { material didático. }\end{array}$ \\
\hline $\begin{array}{l}\text { Preparação } \\
\text { - divisão das } \\
\text { tarefas }\end{array}$ & $\begin{array}{l}\text { Pesquisa de referências em diferentes } \\
\text { mídias para oficina; tutoria de design fiction } \\
\text { durante oficina; auxílio em ferramentas } \\
\text { durante a oficina; e diagramação de material } \\
\text { para o curso. }\end{array}$ & $\begin{array}{l}\text { Quadro de referências de mídias } \\
\text { diversas; Equipe de palestrantes e } \\
\text { equipe de apoio para auxílio durante a } \\
\text { oficina contemplando os softwares } \\
\text { Blender, Maya, autocad, Photoshop, } \\
\text { Illustrator, Rhino, Grass, Sketchup e } \\
\text { Archicad. Diagramação do conteúdo } \\
\text { didático. }\end{array}$ \\
\hline $\begin{array}{l}\text { Critérios } \\
\text { de projeto }\end{array}$ & $\begin{array}{l}\quad \text { Estabelecimento de critérios de } \\
\text { avaliação: Construção de lógica interna; Não } \\
\text { pode ser uma proposta fantasiosa com base } \\
\text { apenas na imaginação; Requer um artefato; } \\
\text { Priorização do relacionamento entre o } \\
\text { usuário e o artefato; e Abandono da noção de } \\
\text { "solução de problemas" }\end{array}$ & Documento de modelo de registro \\
\hline
\end{tabular}

Fonte: elaborado pelos autores, 2021.

Tabela 2. Organização da oficina por dia de atividade.

Dia 1 Apresentação de conceitos chaves com exemplos contextualizados; Apresentação da lista de mídias selecionadas como referencial de projeto; Apresentação de exemplos contextualizados; Divisão dos participantes em equipes de 2-4 pessoas; Alunos devem olhar a listagem de mídias e selecionar uma de referência para seu projeto.

Dia 2 Apresentar os conceitos de narrativa e persona; Apresentar exemplos de aplicação do método em projetos; Discutir o desenvolvimento tecnológico e impactos de novas tecnologias; Início do desenvolvimento das propostas de projeto utilizando o método.

Dia 3 Desenvolvimento das propostas com auxílio da equipe com relação ao método e ferramentas.

Dia 4 Desenvolvimento das propostas com auxílio da equipe com relação ao método e
ferramentas.

Dia 5 Apresentação das propostas desenvolvidas; Discussão dos resultados.

Fonte: elaborado pelos autores, 2021.

A partir dos pontos estabelecidos, definiu-se o papel de cada membro no decurso do projeto: pesquisa de referências em mídias para oficina; tutoria de 
design fiction durante oficina; auxílio em ferramentas durante a oficina; e diagramação de material para o curso. A pesquisa de referências em mídias, no total de 41 obras audiovisuais e literárias, foi organizada na forma de uma tabela, que especificam: o tipo de mídia, o título da obra, o ano de publicação, características fortes e uma imagem de referência.

Por fim, o estabelecimento de critérios de projeto permitiu um registro da proposta, com base nos experimentos prévios descritos no referencial teórico (Markussen \& Knutz, 2013) e no planejamento estabelecido para as oficinas.

\subsection{Realização dos Workshops e Coleta de Dados}

Foram realizados dois workshop com participação de 2 estudantes na oficina piloto e de 4 na subsequente. Apesar do grande número de inscrições, a baixa divulgação do evento nos dias anteriores à sua realização prejudicou o comparecimento de mais alunos. O curso totalizou 20 horas e foi conduzido em três etapas:

- Fase da escrita: os participantes escolhem um mídia de referência e determinam conexões do mundo ficcional com a realidade presente;

- Fase do estabelecimento das regras: desenvolvem as leis ontológicas básicas da permissão e restrição do comportamento das pessoas no mundo ficcional, em comparação com o mundo real;

- Fase experimental: representam as interações dos habitantes do mundo ficcional com a proposta. Construção de personas, micronarrativa, cenário e artefato diegético.

A coleta de dados abarcou observação assistemática, documentada em anotações, imagens e vídeos, realizada de forma livre com base nos critérios (Richardson, 1999): identificar as dificuldades dos alunos em relação às ferramentas e da abordagem de ensino proposta; e a participação na atividade com a entrega do projeto, visto que não era obrigatória.

Cumprindo com o objetivo de explorar as possibilidades de incorporação do método de design fiction no ensino de projeto arquitetônico, os projetos produzidos pelos participantes no decorrer da dinâmica foram analisados de acordo com os critérios pré-estabelecidos (Tabela 01).

\section{$3 \quad$ Resultados e Discussões}

Na primeira oficina os participantes desenvolveram um projeto com base na análise do filme The Maze Runner (2014). Iniciaram com a compreensão das leis ontológicas do mundo ficcional: mundo apocalíptico acometido por uma doença "fulgor"; e presença de uma empresa do governo que recolhe crianças com 6 meses de idade, nascidas em comunidades pobres para servirem de cobaias na busca pela imunidade à doença. 


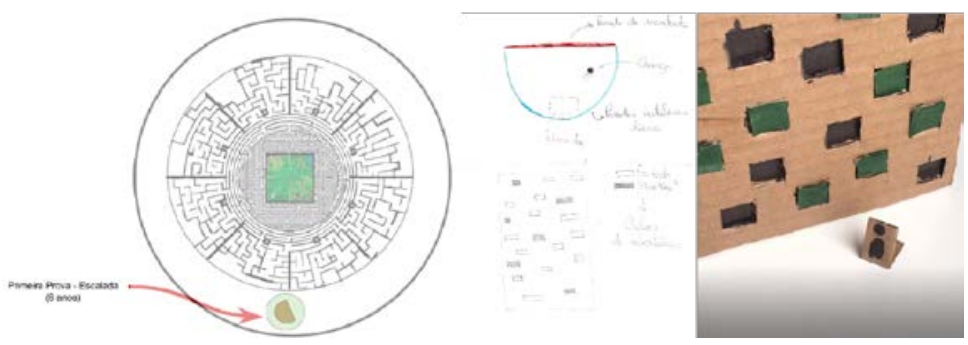

Figura 02. Desenvolvimento do projeto da esquerda para a direita - localização do projeto no contexto do mundo ficcional; desenvolvimento da proposta; e quadro de animação stop motion do projeto. Fonte: elaborado pelos autores, 2021.

O filme se concentra na jornada das cobaias enquanto adolescentes, momento em que são deixadas em um labirinto com outras cobaias sem memórias dos anos anteriores de suas vidas. Com base na história, a dupla questionou o que acontece com essas crianças do momento em que são retiradas de suas famílias até entrarem no labirinto. E passaram a desenvolver uma micronarrativa escrita, com respeito às leis já estabelecidas na história do filme: Ao completarem 6 anos passam pela primeira prova. São dopados e ao acordarem estão em um local escuro e apertado (...) ficam dentro desse caixote metálico se debatendo e socando as paredes até desistirem - trecho extraído do documento de registro dos participantes.

Tabela 3. Desenvolvimento do projeto baseado em The Maze Runner (2014).

Aspecto

Vento e temperatura

Luz:

Como foi trabalhado

"Dentro da fenda é quente, úmido e sem vento. Não há uma brisa sequer. Mas, olhando para cima é possível ver as árvores mexendo lá em cima, com certeza há uma brisa e parece ser muito mais confortável! As paredes metálicas pioram a situação. Refletem os raios solares, ofuscando a visão e tornando o ambiente mais quente ao passar do dia.”

Chão e cheiros

“Após algum tempo as crianças têm seus pés feridos pelas pedras irregulares, eles ardem e doem. Porém, lá em cima deve ter terra, daquelas bem macias e geladas que dão alívio nos pés ao pisar.....é possível sentir o cheiro de terra molhada.....está tão próxima e difícil de alcançar. A cada $2 \mathrm{~h}$ em que as crianças param e não evoluem.....o ambiente fora da fenda tem a programação de acionar um cheiro de comida: carnes, sopa, bolo.....variam conforme as horas vão passando......As crianças, famintas, são estimuladas a seguir o cheiro.”

“O único ponto de entrada de luz é a fenda. De dia o sol ilumina e deixa o ambiente quente (metal). À Noite há apenas a luz do luar, azulada.”

Fonte: elaborado pelos autores, 2021.

A empresa e as crianças foram compreendidas utilizando a técnica de construção de persona, atribuindo-se uma intenção, um desejo e um temor 


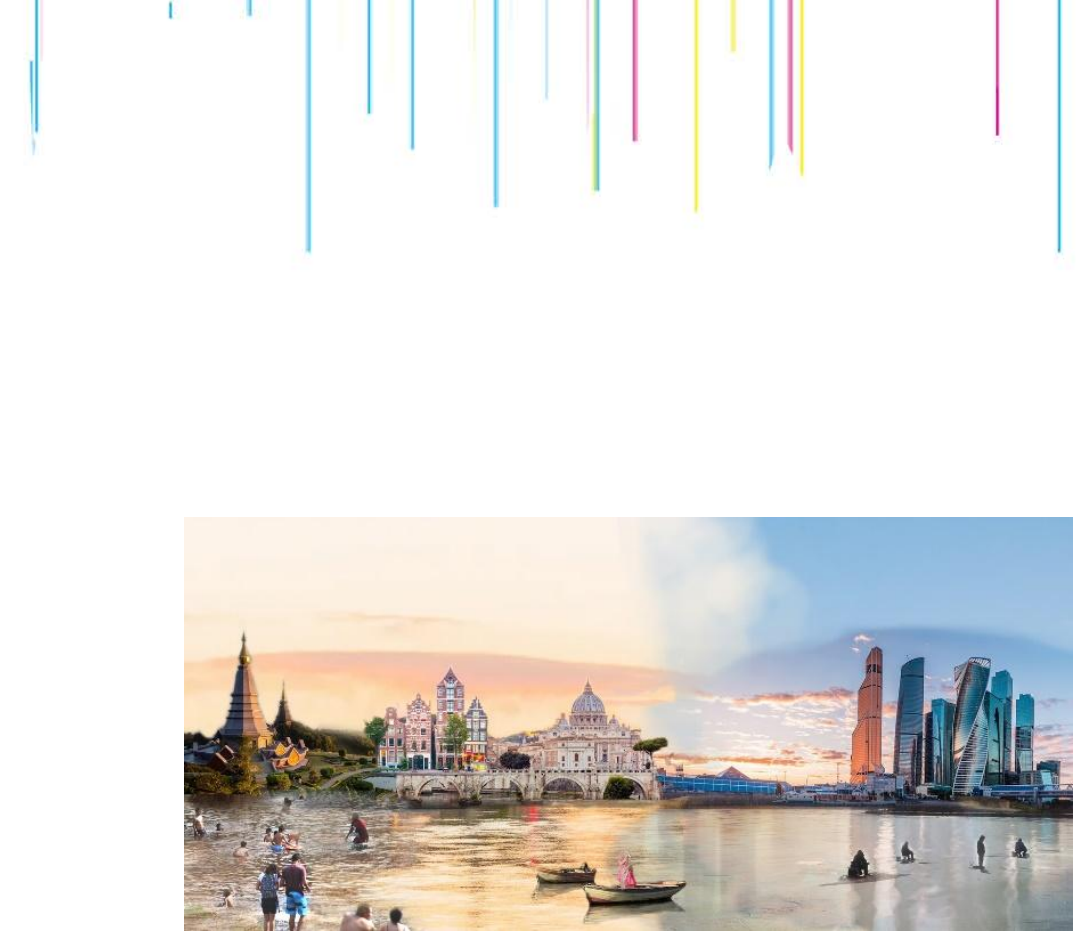

Figura 03. Proposta desenvolvida pela Dupla 1 com base em Chobits (2001 e 2002). Fonte: Os autores, 2021.

Partindo de um posicionamento crítico sobre o mundo tecnológico e individualista, a proposta foca na dualidade na mente da personagem principal, sozinha em uma cidade altamente populosa onde ninguém a vê. O desenrolar do projeto segue a crítica proposta, estimulando o debate sobre nossas cidades - realidades sociais distintas em um mesmo espaço físico.

O projeto propõe a união entre dois mundos - cidade plural: a cidade de Chii (Figura 03) é densamente povoada por persocons e pessoas, com uma postura proativa e alegre, o tempo é sempre bom, tudo tem um tom de lúdico e colorido; a cidade de Freya, é em cores frias, composta de altos prédios de formas racionais e geometricamente perfeitas, menos pessoas nas ruas e pouco contato social. O tempo é frio e ventoso. Embora as cidades sejam contrastantes, o projeto buscou um equilíbrio na representação e na conexão - uma ponte em parte com desenho em arcos e pedra, com ar histórico e romântico e em parte de vidro e metal, reta e funcional.

\section{Arquitetura feita por baratas}

A Dupla 2 questionou o que acontece na Terra enquanto Wall-e está no espaço. A partir dessa lacuna na história representada, buscaram mostrar o que o personagem da barata fez na Terra nesse espaço de tempo. Assim, elegem as baratas como persona para seu projeto, definem existir mais baratas nesse mundo e que, com a partida de Wall-e, decidem construir um mundo como uma imagem de si mesmas. A dupla inicia a compreensão de uma arquitetura feita por baratas a partir de abstrações da forma anatômica de um espécime (Figura 04). Dão seguimento elegendo diretrizes do projeto:

- Orgânico - feito a partir de material orgânico da barata;

- Ventilação cruzada - proporciona conforto térmico;

- Energia solar - a partir das asas e das patas foram criados módulos para captação de energia solar. 


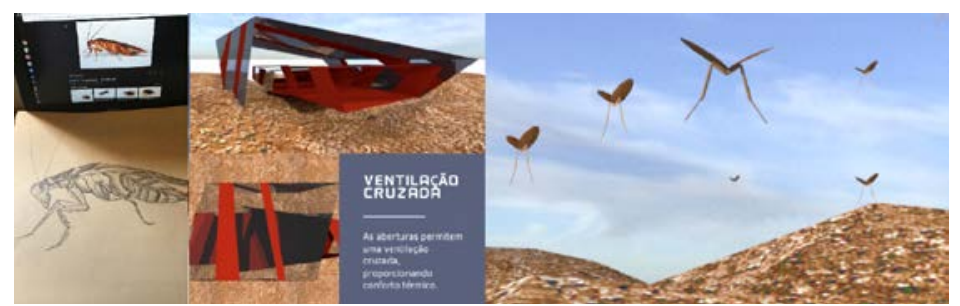

Figura 04. Proposta desenvolvida pela Dupla 2 com base em Wall-e (2014). Fonte: Os autores, 2021.

Em um questionamento crítico sobre o mundo abandonado pela humanidade após ser tão poluído que não sustenta outras formas de vida exceto baratas, a proposta buscou a representação de uma arquitetura ecológica construída pelas baratas. Assim, o projeto provoca o leitor a pensar sobre como construímos nossos mundos e para quem o construímos.

Tabela 5. Resumo do desenvolvimento dos projetos.

\begin{tabular}{|c|c|c|c|}
\hline & Projeto 1 & Projeto 2 & Projeto 3 \\
\hline $\begin{array}{l}\text { Mídia estudada/ } \\
\text { critério de projeto }\end{array}$ & The Maze Runner & Chobits & Wall-e \\
\hline $\begin{array}{l}\text { Construção de } \\
\text { lógica interna }\end{array}$ & $\begin{array}{l}\text { mundo apocalíptico } \\
\text { acometido pelo "fulgor”; } \\
\text { empresa do governo que } \\
\text { usa crianças como } \\
\text { cobaias }\end{array}$ & \begin{tabular}{l}
\multicolumn{3}{c}{ mundo tecnológico; } \\
seres humanos e \\
persocoms; crítica ao \\
individualismo da \\
sociedade que se apoia \\
apenas na tecnologia
\end{tabular} & \begin{tabular}{l}
\multicolumn{1}{c}{ aborda temas } \\
ambientais, Terra não \\
suporta mais vida; \\
humanos vivem no \\
espaço em extremo \\
sedentarismo
\end{tabular} \\
\hline $\begin{array}{l}\text { Não pode ser uma } \\
\text { proposta fantasiosa } \\
\text { com base apenas na } \\
\text { imaginação }\end{array}$ & $\begin{array}{l}\text { Sistema imunológico } \\
\text { e resistência } \\
\text { desenvolvido desde a } \\
\text { infância. }\end{array}$ & $\begin{array}{l}\quad \text { Cidades } r \text { têm } \\
\text { diferentes realidades } \\
\text { sociais em um mesmo } \\
\text { espaço físico }\end{array}$ & $\begin{array}{l}\text { Baratas são } \\
\text { constituídas de proteína } \\
\text { - resistente, pode ser } \\
\text { utilizado na construção }\end{array}$ \\
\hline $\begin{array}{l}\text { Requer } \\
\text { artefato }\end{array}$ & $\begin{array}{l}\text { Primeira } \\
\text { escalada. }\end{array}$ & Cidade plural & $\begin{array}{c}\text { O } \\
\text { sustentável }\end{array}$ \\
\hline $\begin{array}{l}\text { Priorização do } \\
\text { relacionamento entre } \\
\text { o usuário e o artefato }\end{array}$ & $\begin{array}{l}\text { Todo o projeto é } \\
\text { pensado em como afeta } \\
\text { os sentidos e o } \\
\text { psicológico da criança. }\end{array}$ & $\begin{array}{l}\text { O projeto atribui } \\
\text { características distintas } \\
\text { para as cidades e seus } \\
\text { habitantes, mas busca } \\
\text { um equilíbrio. }\end{array}$ & $\begin{array}{l}\text { O pavilhão reflete } \\
\text { uma arquitetura feita } \\
\text { por baratas, como } \\
\text { reflexo delas mesmas, } \\
\text { além de ser sustentável }\end{array}$ \\
\hline \begin{tabular}{ll}
\multicolumn{1}{l}{ Abandono } & da \\
"solução & de \\
problemas" &
\end{tabular} & $\begin{array}{l}\text { Substituído pela } \\
\text { relação entre usuário e } \\
\text { arquitetura. }\end{array}$ & $\begin{array}{l}\text { Substituído pela } \\
\text { relação entre as cidades } \\
\text { e seus habitantes }\end{array}$ & $\begin{array}{l}\text { Substituído pela } \\
\text { relação entre as baratas } \\
\text { e o mundo que habitam }\end{array}$ \\
\hline
\end{tabular}

Fonte: elaborado pelos autores, 2021.

Todos os projetos desenvolvidos tiveram por base a compreensão profunda de uma mídia de referência com suas leis ontológicas, ao mesmo tempo em 
que estabeleceram pontes com o mundo real. Esse processo permitiu a suspensão da descrença em futuros possíveis e o desenvolvimento de uma micro-narrativa, cenário e um artefato diegético contextualizado que reflete a realidade sócio-técnica da mídia selecionada.

Os três projetos desenvolvidos nos dois cursos cumpriram com os critérios de projeto estabelecidos previamente (Tabela 05). Todos desenvolveram uma narrativa alinhada com a realidade percebida na obra, com vista aos efeitos sociais. As extrapolações alcançadas em projeto tiveram como base informações factuais e relações, por vezes críticas, sobre a arquitetura e a tecnologia atual. Todas as equipes entregaram uma proposta de projeto na forma de um ambiente construído dentro da narrativa geratriz, orientando as decisões de projeto com base nas interações e relacionamento entre usuários e artefatos, em detrimento da relação solução-problema.

\section{CONSIDERAÇÕES FINAIS}

Os projetos desenvolvidos exploraram aspectos tecnológicos, ecológicos e socioemocionais dos habitantes dentro de sua narrativa (Tabela 5). Os temas abordados incentivam a exploração de novas áreas como a biologia, anatomia e uso da inteligência artificial dentro do processo de projeto arquitetônico.

A utilização de narrativas e personas foi essencial para direcionar os projetos de forma que tivessem em seu cerne as interações entre artefato e usuário, levando a pensar e representar as possíveis dinâmicas presentes no espaço. A narrativa, a persona e a criação de cenário permitiram delimitar o contexto e ambientação de espaço-tempo do projeto, além de definir os habitantes dessa outra realidade, possibilitando ao aluno novas formas de representar e entender o processo de projeto - o foco do projeto manteve-se no relacionamento e interatividade entre o usuário e o artefato projetado.

Os conceitos encontrados no referencial teórico embasaram o desenvolvimento da narrativa e do projeto arquitetônico de forma condizente com a realidade criada, incorporando a suspensão da descrença sobre uma possível mudança. Neste contexto, foi necessário constante acompanhamento dos palestrantes para que o projeto se ativesse aos critérios pré estabelecidos. A equipe de suporte também mostrou-se essencial, sendo requisitado auxílio de ferramentas específicas ao longo das oficinas, como softwares de modelagem paramétrica.

Futuros experimentos com um número maior de participantes e em uma estrutura de maior duração serão desenvolvidos, buscando compreender a construção de mundos possíveis mas não preditivos como gatilhos para 0 desenvolvimento das etapas iniciais do processo de projeto em arquitetura. 


\section{Referências}

Bleecker, J. (2009). Design Fiction: A Short Essay on Design, Science, Fact and Fiction. http://drbfw5wfjlxon.cloudfront.net/writing/DesignFiction_WebEdition.pdf

Broadbent, G., \& Ward, A. (Eds.). (1969). Design methods in architecture (No. 4). Wittenborn Art Books.

Coleridge, S. T. (1817). Biographia Literaria. Princeton: Princeton University Press.

Kirby, D., (2010). The Future is Now: Diegetic Prototypes and the Role of Popular Films in Generating Real-world Technological Development. Social Studies of Science, 40(1), pp.41-70

Knutz, E., Markussen, T., \& Christensen, P. R., 2014. The Role of Fiction in Experiments within Design, Art \& Architecture - Towards a New Typology of Design Fiction. ARTIFACT. v III, Issue 2. pp. 8.1-8.13

Lawson, B., (2011). Como arquitetos e designers pensam. São Paulo, SP: Oficina de textos.

Lupton, E., (2017). Design is Storytelling. New York, NY: Cooper Hewit, Smithsonian Design Museum.

Murray, J., H., (2017). Hamlet on the Holodeck: The Future of Narrative in Cyberspace. MIT Press, Londong, England.

Plowright, P. D., (2020). Design fiction and architecture. Anais de EAAE -ARCC International Conference, Valência, Espanha, 2.

Richardson, R. J., (1999). Pesquisa social: métodos e técnicas. 3. ed. rev. ampl. São Paulo: Atlas

Ryan, M., 2001. Narrative as virtual reality: immersion and interactivity in literature and electronic media. Baltimore: The Johns Hopkins University Press.

Schon, D. A., (1984). The Reflective Practitioner: How Professionals Think In Action. Nova York: Basic Books,

Markussen, T., Knutz, E., (2013) The Poetics of Design Fiction. DPPI'13, Newcastle upon Tyne, UK.

Sterling, B., (2012). Bruce Sterling Explains the Intriguing New Concept of Design Fiction (Interview by Torie Bosch). Slate. http://www.slate.com/blogs/future_tense/2012/03/02/bruce_sterling_on_design_fic tions_html

Tanenbaum, J. (2014) 'Design Fictional Interactions: Why $\mathrm{HCl}$ Should Care About Stories', Interactions (September), pp. 22-23. 